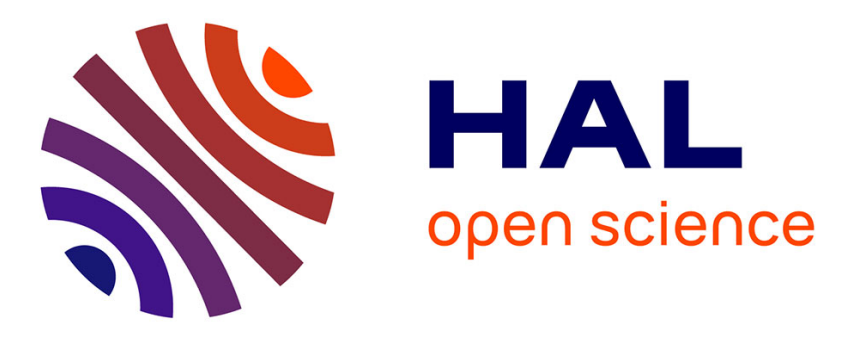

\title{
THE TRUTHS OF INTERPRETATIONS Envy, possession and recovery in Ladakh
}

\author{
Patrick G. N. Kaplanian
}

\section{To cite this version:}

Patrick G. N. Kaplanian. THE TRUTHS OF INTERPRETATIONS Envy, possession and recovery in Ladakh. In Beyond Textuality: Asceticism and Violence in Anthropological Interpretation Sous la direction de Gilles Bibeau et Ellen Corin 378 pages, collection Approaches to Semiotics Mouton De Gruyter (Novembre 1994) ISBN-13 : 978-3110138894, Mouton de Gruyter, 1994, Approaches to Semiotics, 978-3110138894. hal-02504778

\section{HAL Id: hal-02504778 https://hal.science/hal-02504778}

Submitted on 11 Mar 2020

HAL is a multi-disciplinary open access archive for the deposit and dissemination of scientific research documents, whether they are published or not. The documents may come from teaching and research institutions in France or abroad, or from public or private research centers.
L'archive ouverte pluridisciplinaire HAL, est destinée au dépôt et à la diffusion de documents scientifiques de niveau recherche, publiés ou non, émanant des établissements d'enseignement et de recherche français ou étrangers, des laboratoires publics ou privés. 


\title{
THE TRUTHS OF INTERPRETATIONS
}

\author{
Envy, possession and recovery in Ladakh
}

Patrick Kaplanian

What sort of relationship exists between indigenous interpretations and the interpretations of Western ethnologists? This is a vast question that requires one major clarification before embarking upon its response. That is, we must distinguish between the facts which exist outside of a native's interpretation and the facts which are constituted by the interpretation itself. The following examples should serve to clarify this issue.

\section{Two love stories}

\subsection{Case 1}

The Ladakhis ${ }^{1}$ tell that their King Jamyang Namgyal (spelled 'jam-dbangs rnam-rgyal) was defeated by the makspon (dmag-dpon) of Khapalu at the beginning of the seventeenth century. The King was taken prisoner and had as his jailer the makspon's own daughter. They fell in love with each other and she soon found herself pregnant. One day, the makspon had a dream where he saw his daughter giving birth to a lion. Full of suspicion, he had her examined, and, realizing the extent of the damage to his daughter, his heart was moved. Then he set the King free, gave him his daughter and allowed them go away together.

This story has every aspect of a myth in that it is not plausible (implausibility being a common, but not essential feature of myth). The fact of its implausibility is, however, less important to our analysis than the way in which it is treated as such by the ethnologist.

The historian can always set forth his own "counter-truth" which pretends to refer back to reality. The above events are historical. They indeed occurred in Ladakh in the beginning of the seventeenth century, regardless of how the Ladakhis relate them. The historian, basing his understanding on documents other than those handed down by word of mouth, can demonstrate what personal interest the makspon had in being magnanimous (for instance political alliance with the defeated but unsubdued country, transfer of land, concessions to Islam, peace treaty permitting to look towards new horizons, etc.) and may prefer to base his research on epigraphical or archeological evidences.

The work of the historian is based on objective reality, that is to say, on facts which escape individuals. But a mythical story is not, for all that, uninteresting. It provides a subject of study for the ethnologist and refers to mental structures, to the Ladakhis' conception of their past and present.

The historian tending to be interested in popular accounts from a heuristic point of view (they can give an indication of reality, without proving anything, not even King Jamyang Namgyal's existence) will refer to more tangible elements: genuine texts, decrees, edicts, letters, inscriptions, testimonies.

\footnotetext{
${ }^{1}$ The Ladakh is a region lying North-West of the Himalayas. Politically, it is a part of the Indian Union but being situated exactly beyond the great Himalayan range, it is geographically and culturally a continuation of the Tibetan High plateau. Ladakhis speak a Tibetan dialect. They are roughly half Muslims (mainly Shiites duodecimin with a few Sunnites) and another half Buddhist-Lamaist. The latter have been the subject of my study since 1974.

Transcriptions are given phonetically after the Ladakhi pronunciation. They are followed (between bracket or preceded with spelled) with a transliteration of the equivalent word spelled as it is in Tibetan.
} 


\subsection{Case 2}

The Ladakhis believe that the "spirits" $(\operatorname{sem}(s))$ of some envious people (which they call gongpo, fem. gongmo, spelled 'gong-po, 'gong-mo) can possess the bodies of those people they envy.

For instance, Tsewang tells that his wife Dolma was once possessed by his own brother. When a person is possessed, he or she is taken hold of by various means and acts as the mouthpiece of the possessor. Tsewang's brother, while inhabiting Dolma's body, voiced his desire for her. Since then, she has never again been possessed. Like the historian, the psychoanalyst can put forth his own interpretation: that Dolma herself is speaking and that it is Dolma who feels the desire for her brother-in-law. This illustrates another point of view and the Western psychoanalyst may believe no more in gongpo than the historian does in Jamyang Namgyal's beautiful love story.

There is a great difference between case 1 and case 2 . In case 1 , objective historical events did take place independently of the way they are related. As for Dolma's story, it can only take place in a country where one believes in gongpo (although there are cases of hysteria in the West where the patient assumes the voice and gestures of another). In other words, in the case of Dolma, the facts are inseparable from the interpretation given to them by the natives. Struck with the same desire, Dolma would have probably reacted differently in the West via conversion hysteria, phobia, obsessional neurosis or even paranoia.

But does she feel the same desire? Is the psychoanalyst's counter-interpretation grounded? If Dolma's case is no more than conversion hysteria of a paroxysmal type, the "fit" will have proved ineffectual and Dolma will relapse one way or another. There is no tracing back the associative sequence, nor any abreaction, but on the contrary, an even stronger feeling of being persecuted may occur due to the intervention of the social surroundings, possibly with the approval of some authorities such as the scholar, the lama, the astrologer, or even a deity uttering revelations through a professional oracle, the luyer, spelled lus-gyar (see note 7).

Thus, if we are to maintain this assumption of inversion (it is Dolma herself who is in love with her brother-in-law), then recovery as the result of a trance would remain non understandable from a psychoanalytic point of view. At the very most we can speak of a hallucinatory satisfaction of the desire, for the trance is equivalent to a dream. Yet a hallucinatory fulfillment has never brought about recovery. However, this story occurred only once (although it may occur again but not indefinitely).

It is true that the trance induces a manipulation on the part of the social circle which takes hold of the possessor through Dolma's body and makes it speak: "who are you?", "I am so and so", "what do you want?", "I am in love with Dolma". This procedure "objectifies" the presence of the possessor and reinforces its existence... On the one hand, the brother-in law is actually in Dolma's body. On the other hand, everything occurs as though Dolma, projecting her desire on another person, were indeed meeting this other person who expresses his desire for her and thereby confirms what she has said.

The fact remains that from a psychoanalytical viewpoint this objectification is insufficient. Dolma would not recover without going back to the repressed representation that is to say to the acknowledgement of her desire for her brother-in-law. 
In the first case, the historian can propose a transcultural interpretive framework based on the assumption that interpretations lie in facts or inexplanatory principles which are assumed to be universal. The ethnologist may likewise make local interpretations taking, for example, King Jamyang Namgyal's legend as a subject of study.

In the second case, the psychoanalyst cannot follow the same process as the historian, whereas the ethnologist can analyze the gongmo manifestations by studying the local interpretations as such - that is to say exactly the way he analyses myths. In both cases, the historian and the psychoanalyst are in radically different positions. As for the ethnologist, he is in a similar position although not identical, due to the fact that in the Jamyang Namgyal legend, he has to deal with one object only: that being the story itself. In the case of gongmo, he must deal with two elements. First, he must examine the belief in gongmo, which constitutes an important element of the background and framework of interpretation in Ladakhi culture; and second, he must explore concrete instances such as Dolma's, which must be analyzed while taking into account that Dolma believes in gongmo.

In principle, the ethnologist tries to throw light on the meaning of a myth through the knowledge of the culture itself, but his interpretation is not necessarily the same as the popular interpretation. It can thus lead to another interpretation, different from that of the historian; that is, a fraction of the so-called objective reality. As for the psychoanalyst, he has a pretheory for which he seeks confirmation, just like the Ladakhis when they speak about gongmo.

Without making allowance for this belief in gongmo, one runs the risk of falling again into a "slapdash psychoanalysis", an artificial adjustment of its fundamental concepts. However, as we have just seen although there is no satisfactory explanation of the phenomenon of gongmo, it does have a certain therapeutic effectiveness. How can an interpretation external to a culture account for the therapeutic effectiveness of certain beliefs or rituals founded on an interpretation internal to this same culture? This is the question being put to the ethnologist.

The provisional conclusion is that psychoanalysis has not the same status with regard to a possessed Ladakhi woman than history does with regard to a Ladakhi myth. Thus psychoanalysis refers back to a particular context, that being the "modern Judeo-Christian" West, and therefore lacks authority in providing explanation for the phenomenon of gongmo.

Ellen Corin has said:

"The analyst and the person analyzed are two entities which have their roots in a very particular culture. This culture consists of the knowledge, points of reference, symbols and values through which the members of a society interpret their experience and construct a world view which is appropriate to them. From the time that these elements are integrated into a world view, this vision takes on the status of 'reality'. It implies certain particular conceptions of man, his foundations and his relationship to others. From this position of culture and the postulates which follow, we formulate the systems of knowledge in each society; it seems implausible that the project of analysis could be detached from this culturally derived discourse on the meaning of man and the world. Thus, how can we ignore the fact that the particular way in which we view history, or the special 
importance accorded to autonomy in the development of a person are characteristics of a culturecontext which is both Judeo-Christian and modern?" (1985: 54)

In other words, cases should be studied while considering both the therapeutic systems and the systems of belief of a given culture. An ethnologist attracted by the West should be equally interested in neurotics as in psychoanalysis. The point we are left with is that psychoanalysis, connected as it is with a given culture in a given period, cannot provide us with an appropriate explanatory framework for the understanding of the gongmo phenomenon.

We must then turn to another explanation. Mine is as follows: We must introduce the "social dimension" of recovery, for it is obvious that it is not pure coincidence that the given case involves a brother-in-law. This might not surprise a Western reader, as instances where a woman is in love with her brother-in-law are frequent, but we must beware of importing such Western standards to other societies. Some, though not all, Ladakhi people practice adelphic polyandry. In this context, Dolma's case appears in a very different light, for the social infrastructure brings everything back to its place: the brother-in-law is not seen by family and friends as a possible second husband. The problem is that of familial and/or social identity: that of Dolma's status. In order to demonstrate what I have up until now stated peremptorily, I shall first describe the gongmo in more detail, then I shall analyze three specific examples.

\section{The gongmo}

To begin with, I will describe a few ethnographical elements about the gongmo (masc. gongpo. As it concerns almost exclusively women, I will use the feminine gongmo). They are not necessarily persons whose "soul" (in the Western acceptance of the term) leaves the body in order to inhabit the body of someone else. During the possession, the possessor might well be unconscious, but very often he goes about with his business. He just thinks of the victim of whom he is jealous, and it is this very thought $(\operatorname{sem}(s)$, spelled $\operatorname{sems}$, word which also translates as "spirit" or "soul") which inhabits simultaneously the victim's body.

Envy is the main motive, which should not be surprising in traditional societies where it is considered bad form to attract attention by conspicuous prosperity. Many possessed individuals complain of being victims of envious rivals, just because they have been successful. One such woman complained of having been possessed, because she had succeeded in dominating the household (Kaplanian 1983); another claimed it was because she was very hardworking (Kaplanian 1981) which enabled her to be married above her class. ${ }^{2}$

In order for possession by a gongmo to occur, the possessor has to be wicked and foster evil thoughts. A woman's spitefulness is to be attributed to the presence of a demon ( $d e$, spelled 'dre) in her. More precisely, the demon which dwells in her left shoulder is more powerful than the "god" (lha) in her right shoulder. As a matter of fact, Ladakhi people believe that each individual carries a $d \mathrm{e}$ in his left shoulder, and in the right shoulder a lha. Whenever someone appears before the god of death, singe chogyal (gsin-rie chos-rgyal) his lha puts down white stones on the scale of a balance and his de puts black stones on the other scale, this of course occurring after death. But before

\footnotetext{
${ }^{2}$ In Ladakh girls who have the chance to make an hypergamic marriage are not the more beautiful but the more hardworking. See Kaplanian, 1981: 216 .
} 
death, so long as the de is the strongest, the individual is wicked This is the case with the gongmo, evil to such a degree that the individuals can, in a sense, be assimilated into a $d \mathrm{e}$, when the $d \mathrm{e}$ is very powerful.

This power of the gongmo's de expresses itself in a different way as well. Along with the existence of the pair lha/de in the shoulders, there is also another concept according to which the lha occupies the body and the de, the shadow.

Gongmo are also currently called gyabi țimak (spelled rgyab-gyi krimag, "shadow of the back"). When one is said to be: "kho gyabde nganpa", "the de of her back is evil", it means that "she is a gongmo". We will see an application of this conception a little further on.

So, gongmo are wicked (nganpa) woman with a powerful de who harbor evil thoughts (semngan, spelled semsngan) towards others. Most often such thoughts are caused by envy. A gongmo has only to think with envy of someone else in order for that person (who may not even know the gongmo) to possess: this is because her thoughts $(\operatorname{sem}(s))$ can at once take possession of her victim. Bodies cannot move about quickly, whereas thoughts $(\operatorname{sem}(s))$ can move instantaneously from place to place. The spirit of the possessed is driven out of the heart and replaced by that of the possessor (zhuksk(h)an, spelled zhugs-mkhan). The possessed then speaks with the possessor's voice. There are many ways to get rid of the possessor:

(1) by ignoring him, by waiting for him to get tired;

(2) by holding both the victim's middle fingers and asking the possessor to state his identity and what he wants (this can be done by anyone present). Some must be dealt with gently, otherwise the possessor's $\operatorname{sem}(s)$ may flee without having been identified. In other instances, the victim has to be beaten up (in reality, it would be the possessor who is beaten);

(3) if this fails, one can also beat the shadow of the back (gyabi țimak, spelled rgyab-gyi kri-mag) which is the demon's favorite abode;

(4) it is also possible to blow the smoke of a piece of cloth burned in a fire over the victim or better yet, the smoke of some object on which a rinpoche (rin-po-che, reincarnated great lama) has previously blown after reciting mantras (formulas). Most often, colza seeds (nyungskar, spelled yungs-dkar, white mustard) are used and this phenomenon is called dugzes (dug-rdzas);

(5) colza seeds are plant blends that give off an appalling smell when thrown into the fire and this smell is likely to reduce the possessor's resistance;

(6) finally, there is an extremely effective means which consists of asking the possessed to lick a shoe. It is well known that the sole is a redoubtable soil (tip, spelled sgrib). The aim is to poison the possessor, not the possessed, and to weaken him.

It is worth noting that the second operation is the most common and the most commonly mentioned. In most cases, it is enough to force the possessor to state his identity. The victim's middle fingers are held together, one on top of the other: the middle finger is said to be the delak ('dre-lag, the demon's finger) ${ }^{3}$. The middle finger is not only the finger through which the gongmo are overpowered; it is also the finger through which they get in and out. One

\footnotetext{
${ }^{3}$ The ring finger, frequently mentioned in Tibet, is much less mentioned in Ladakh.
} 
informant stated that this middle finger leads to the heart in the middle of the body ${ }^{4}$ and that in order to keep the gongmo from getting in, one wears a ring around it.

This presentation is naturally highly theoretical and we seldom encounter concrete cases which correspond to it exactly. The reader may realize that Dolma's case, which is rapidly described above, already proves to be uncharacteristic. Not so much because it is about possession by a man (which is rare but not nonexistent) but above all because the motives of wickedness and envy seem to be absent. Too many elements are lacking to analyze it in more detail. It is nonetheless perfectly authentic and I have chosen it because it easily lent itself to "Western-style" analysis. In order to support this demonstration, I will draw from three cases, that of Tashi, M.T. and Chorol.

\section{Three cases of possession}

\subsection{Tashi's case}

It is A., the oldest of four brothers and two sisters who tells us this story. He spontaneously specifies that the family property was divided up between four brothers and two sisters. He also specifies, just as spontaneously, that this form of property division was a change from the traditional practices "This being new at the time" (it was about tenfifteen years $\mathrm{ago}^{5}$ ). One of the sisters, having married outside of her circle, finally gave up her share of the land, which was consequently divided up among the five others. The other sister took her part with her in the context of a virilocal marriage. This system was in fact new ten-fifteen years ago and is still new today.

The traditional system requires that the property remains undivided. The woman marries one, two, or even three brothers and the others may become monks or may marry uxorilocally in a family where are only daughters (Kaplanian 1981). A. married Tashi, and according to the new rules, Tashi took her part of the family land with her. A.'s cousin (the son of his mother's brother, to be precise) married Diskit who came from another family and brought her portion of land with her into the family of A's maternal uncle. As it turned out, however, A's cousin died and Diskit found herself a widow After that, a marriage was seriously envisaged between Diskit and one of A's younger brothers.

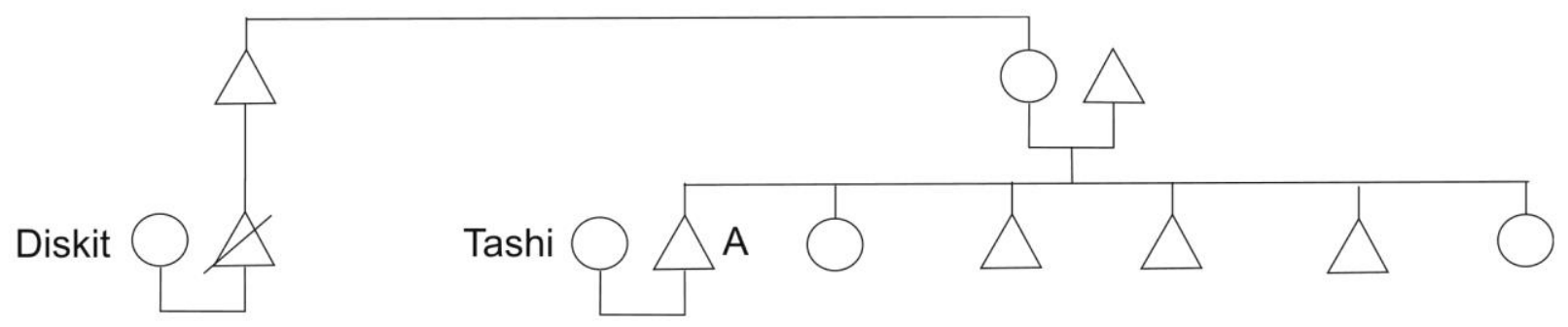

\footnotetext{
${ }^{4}$ The heart as the seat of the "spirit" $(\operatorname{sem}(s)$. The $\operatorname{sem}(s)$ of the gongmo comes in dislodging that of the possessed.

${ }^{5}$ The interview took place in 1985.
} 
Finally, A. said, "we gave it up. We wanted to remain on good relations with the uncle's family" (that is, allies). However, with this new system, it would have been necessary for Diskit to take her part of the land with her, an act which would have been seen as self-seeking by the uncle.

It is at this moment that Tashi was possessed by Diskit. This happened only twice. Then Diskit, resigned, never came back into the body of Tashi. During the trance, Diskit reproached Tashi for being responsible for the break up of her marriage with one of her brother-in-laws: "It's you who was opposed to it, it's your fault if I was not able to marry your brother-in-law".

As in the case of Dolma, the interrogation (by Tashi) has to do with her social status. We are, let us not forget, in a new system of both parental relations and land inheritance. The refusal by Tashi's family to accept Diskit creates a problem for Tashi. Why is it that in two analogous situations, the response of Tashi's circle is different? Tashi's identity is at stake for she is being suddenly put in danger. In this patrilocal system, she is being menaced. Any person in a similar case to her's would be rejected by the family, where they had formerly been accepted. In Tashi's case, she suddenly questioned the family group in which she had been received as to her status. What's more, she summoned the claimant into her own family in order to have her expelled.

In a given society where the status of a person (or of the subject, as it were) is above all defined by the rules and laws of society, the place of this person, i. e. his or her social and parental status within his or her family, stands for person, their identity.

But the change of rules concerning family bonds and inheritance create new problems. In Tashi's case, she finds herself confronted with patterns which are not necessarily those instilled into her through her own education. Hence the necessity for a recentering.

Does this mean that the dimension of the individual itself is nonexistent? Surely not. The exclusion of Diskit confers upon Tashi a certain superiority while she reintegrates the social-parental fabric. She has been elected but not her rival. At the same time as she is being reinstated into the new norm, Tashi sees herself as having been granted a certain superiority.

Thus, Tashi's case clearly illustrates what I had said in a more general fashion about the gongmo: while envy is the main motive the envied person is out of phase in relationship to the norm. The person is either above the norm (i.e. exceptionally prosperous which would justify this jealousy) or she is outside of the norm (non-polyandric marriage for example). Finally, they may be within a new norm that needs to be confirmed, assured and affirmed (Tashi's case).

The "inversion" that I earlier credited to the psychoanalyst is, therefore, only partly valid. It is not so much Diskit who is jealous (although she has objectively every reason to be so), but Tashi who needs to be confirmed of her over-valorization, in her privileges. The rejection vis-à-vis Diskit puts her in danger and although there is indeed a certain inversion, there is no projection because Tashi is really privileged and Diskit is effectively at a disadvantage. The question asked by Tashi which is attributed to Diskit is relevant because one does not actually see why she was accepted with her part of land, when Diskit was not. The explanation given by A. to the ethnologist (and, in all likelihood to Diskit and Tashi as well) does not satisfy Tashi, for if A. and his brothers did not want to be suspected of being self-seeking by their maternal uncle, they did not mind being so by Tashi's father. We might object that 
Tashi could understand very well that her brother-in-law wanted to keep on good terms with the uncle and that her case was different. Maybe she could have understood it if the partition system of property had not been new and therefore not yet consolidated. It must also be taken into account that the decision to renounce this marriage with Diskit was probably made by the men.

A second example will demonstrate that the gongmo phenomenon becomes clearly evident when dealing with the strengthening of a social position which is outside of the norm.

\subsection{M.T.'s case}

M.T. has been through higher education. He has a stable and interesting job. He reads, writes and speaks Tibetan, Urdu and English. He is seemingly diametrically opposed to Tashi. He married the girl he was in love with and against the will of her parents. They had to elope together to Chandigarh to have their marriage registered before the Indian Civil administration. On their return, his wife reconciled with part of her family and it was decided that they would have a traditional Ladakhi wedding in order to "legalize" the situation.

The day before the wedding, M.T. showed signs of discomfort. He had, it seemed, a slight fever and his legs and back were aching (back ache often bodes possession). I asked him, teasingly, if it was not a case of (s)notpa ${ }^{6}$. He dismissed my remark with a wave of the hand and asked me for some medicine. I had none and so he went to bed.

On the next day, the wedding took place as planned without any unexpected incidents. I was amazed, however, to find M.T. at a lhamo's (oracle) ${ }^{7}$ séance about ten days later. After the session, he told me that he was suffering from mirdeces (faintness which often bodes possession). Another girl was in love with him. This girl's mother was a gongmo and the likelihood was that her daughter had become one as well, especially with the resentment she might have felt after M.T.'s marriage. He thought he was the victim of possession attempts by this neglected girl.

Of course, the case here is completely different from the former. M.T. disregards the rules of this society (love marriages are very rare) but he needs to be reintegrated. His bride's family still does not accept the fait accompli, so he organizes a traditional wedding. There, the procession does not begin at the girl's parents' house (as is the tradition) but goes from the house of the eldest of the bride's aunts, who agrees to play the part of her mother in the wedding.

This half-successful reintegration leads to the outbreak of possession by a gongmo. The gongmo in question, that is, the girl who was assigned to him by his family circle, is not summoned and therefore cannot be solemnly expelled by M.T.'s family.

M.T. is then compelled to resort to the lhamo, the oracle, or more precisely, to a deity who speaks through the oracle (see note 7) and who supports him in his choice. The lhamo had actually declared: "You went westwards" (direction of the young girl's village) "you did well to get married".

\footnotetext{
${ }^{6}$ The Buddhists of Ladakh call (s)notpa (gnod-pa) and sometimes rdon (gdon), skyon (skyon) or gek (bgegs) any kind of damage due to supernatural entities. The (s)notpa may well break out in the form of a drought, poverty, animals dying, etc., as physical or mental illness. The word ( $s$ )notpa applies also to damages caused by gongmo. For further details see Kaplanian 1990.

${ }^{7}$ It is worth nothing that whenever the treatment described above fails, one resorts to a luyer (lus-gyar). It is a person whose profession is to be possessed by a deity who speaks through her and answers the questions. See Brauen 1980 and Day 1989. In so far as he is possessed, the luyer is called lhaba (Iha-pa) fem. Ihamo (Iha-mo).
} 
Therefore, M.T. is not above the norm, or in a fragile new norm. He is, rather, partly outside it, and this through his own personal choice. I say this partly because love marriages are tolerated (on this subject see Phylactou 1989). His status as an "intellectual" fluent in foreign languages and as a wage earner (he is a book-keeper) in a traditional peasant family, was already a dephasing factor.

\subsection{Chorol's case}

The story is told by S. Day:

"At times, Chorol looked tired and pale; she used to retire to her room for two or three days at a time to sleep. She gave up cooking, shopping and agricultural work during these periods though she only missed a few days of work as a caretaker in Leh. At these times, she complained of pains in her back and sometimes also in her arms.

(...) No one was very clear what was wrong. The first signs of illness, in August, were a sore throat and a cold which got worse and worse. Chorol lost her voice for several days. She also developed boils which, she said, did not get better until the end of September. When I asked what was wrong, the family usually said they didn't know; sometimes, they said "she's lazy and stupid" and, when she had complained of back ache, they sometimes claimed "its gongmo, it must be gongmo, Chorol has been possessed before". They thought that amulets from the village monk might help and they told anyone who asked, "she's got a bad throat and she's resting"". (1989: 341)

Although mirdeces are symptoms boding possession, as well as back aches, nobody really suspects such a diagnosis from the beginning.

When it becomes clear that it is a case of possession, the wrong diagnosis and the symptoms that do not coincide with those of possession will be forgotten (sore throat, boils). Only later will the diagnosis of possession be delivered by the lhaba (orth. lha-pa, oracle, masc. of lhamo) after a first fit.

"In August, Chorol's brother came home late one night. He was just about to go to bed when Chorol's younger sister rushed in, terrified. Chorol had suffered zhugshes [possession] for five minutes; she had laughed hysterically and her eyes were rolled back so that you could see only the whites. On Saturday, Chorol and Tsering (the younger sister) sent the child to look after the cows. Then, they locked the door so there must have been signs of approaching zhugshes. Still, the gongmo managed to get in. Chorol had slight convulsions and she breathed in sharply. Then she became possessed. She laughed hysterically again just like the Indian film stars in Hindi movies and said that she remembered nothing about the episodes. 
Chorol said that something must have happened a month later. She remembered nothing except that her husband was very frightened and cried. Over the next three days, there were further episodes. One brother described what happened when he was alone with Chorol: "She cried and screamed a lot. I could have stopped it if I'd had my ritual dagger (phur-pa). Instead, I read texts. Chorol snatched the book from me and began to read in Bodi (that is, in Tibetan) which Chorol does not normally claim to understand." (Day 1989: 344)

Let's point out in the above lines the importance of the other's presence. That is why, as mentioned above, possessed and possessor begin by ignoring each other, which was Chorol's younger brother's attitude: "I ignored her. You must not talk (to an affected person) then, because the attention might encourage possession. If you ignore her, the gongmo might go away".

After this method had proved ineffectual, he tried the finger test:

"I grabbed her two middle fingers hard, SHE [the gongmo] hid her face and tried to cover her shadow which I wanted to beat. Then, she came round and almost cried. She must have realized what had happened because I was still holding her fingers."

This also failed, and finally they had to resort to a lhaba. One of the brothers recounted: (capital letters stand for the deity who speaks or acts through the oracle).

"I finally persuaded Kirzi oracle to come. He stayed out all night. He came into trance and, first, he sucked something out of grandfather's leg, saying that meme (grandfather) was ill because he drank too much. Then, he sucked something from Chorol's stomach. He put mustard seeds in the fire and blew the smoke over Chorol. He blessed her and immediately grasped her two middle fingers.

But the bamo $^{8}$ came and went very quickly. He called her Yangchen and said that she was the girl from L. Main house. Just as he was about the beat the bamo with a stick, Chorol said, 'No, don't, I'm not possessed'. Yangchen's grandmother was also possessing Chorol, he said, but she didn't appear at all. Because the gongmo went so quickly, the god couldn't ask the normal questions. He stayed all night in case they should return, but they didn't.

The god said that an amulet would cure Chorol so we got one for her next day and we also took her to Tak Tok rinpoche who gave her a khapko blessing. Khakpo is the name of a ritual, bamo is here synonym of gongmo." (Day 1989: 346).

We will note the fact that the mere disclosure of the possessor's name was enough to stop the possession. This took place in September 1982, whereas the first fit above described had happened in August. Chorol then left her village

${ }^{8}$ Bamo, witch. Here she means gongmo. 
laying 15 kilometers East of Leh for Leh, the "capital" of Ladakh and came back in December. The signs of possession reappeared. The oracle of Kirzi was called upon again:

"In this way, he managed to collect five gongmo. Then HE sent everyone out of the room except for Chorol and he told the witches to come back with the people. They came back ten or fifteen minutes later. (...)

The oracle came back into trance from about 3:00 to 4:00 that afternoon. The god said the witches had only gone as far as Chorol's throat. HE told them to go to her heart so that they might speak. Then, they would be easier fo finish. HE said that the witches had come to Chorol three days ago. HE also said that they only came when she was in [her village] not in Leh. HE did not reveal their names, but HE pointed out the directions which suggested their origins. All were from the village. HE gave Chorol and amulet which was a welcome scarf with three knots containing barley. HE told her to keep the amulet with her. HE said that HE would take responsibility and she would suffer no possession for a year. Then, HE turned to the other people, to treat them." (Day 1989: 347)

If I dwell on this story, it is not only because S. Day gave a very detailed description of it, but also because this household constitutes an exceptional area of observation. S. Day lived in this family from 1981 to 1984 and previously another ethnologist made long stays there between 1976 and 1983 and even later as he last visited them in $1988^{9}$. I have had myself the opportunity to pay frequent visits to the members of Chorol's family since 1977.

At the time of the events, the household consisted of an old widowed father and six children. The youngest Tsering was a secretary stationed 200 kilometers from the household. She did not live with her brothers and sisters.

Two of the brothers who were divorced had kept their young boys with them (it was a polyandric marriage)

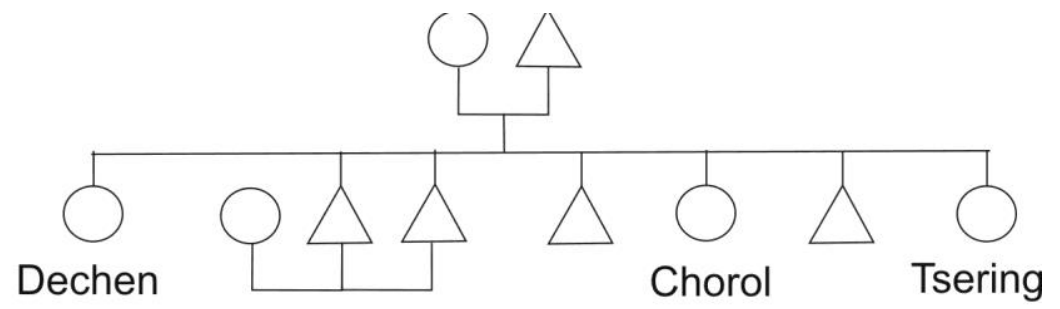

Although they are all well within marriageable age (the youngest was twenty years old in 1982 and the eldest thirtytwo), none of them was in fact married, which denotes an already highly unusual situation (the reasons for which are however unclear). In 1981, Chorol told the first ethnologist that she was afraid she might remain an old maid.

\footnotetext{
${ }^{9}$ According to the first ethnologist who stayed with this family, the wife of the two brothers had divorced (before her arrival in 1977) because she could not get along with Dechen, the eldest sister. Rivalry between sisters-in-law is frequent. As for Chorol's apprehensions, it is the contrary that could have happened.
} 
Moreover, should a sister-in-law enter the family, she ran the risk of being thrown out of the house (the system here is a patrilocal one).

At the time of the events, Chorol ran away from home with the youngest son of a well known amchi (traditional doctor). But the son had a very bad reputation (he was addicted to drinking and he was also lazy). Both families were against this marriage where, unlike M.T.'s case above, not even the minimum rules prescribed in such cases had been respected (Phylactou 1989). What's more, Dechen, Chorol's eldest sister was terribly annoyed at having lost a precious source of help in the household. The couple settled neolocally in Leh. In short, Chorol stands out of the norms to the point of caricature.

In 1984, I met Chorol who had settled back in her family with her husband and their baby. I was told that they had agreed to an uxorilocal marriage which surprised me: uxorilocal marriages in Ladakh only take place in families where there are only daughters (or at most only one boy, much younger than his sisters).

Actually having partly reconciled with her family, Chorol used to sail to and from Leh to her father's house with her husband and son. As S. Day says: "At that time, it was unclear where Chorol and her husband were living” (p. 169). The main possessor of Chorol is Yangchen, her best girl-friend (most often, possessor and possessed are closely related) but above all, she is an "old maid" who is jealous of Chorol's marriage. Of course, as in the other cases, Chorol, who acts on her own authority and totally outside the rules of her society, needs to be confirmed in her choice: hence the necessity of Yanchen's envy. We even learn that Yangchen "had been in the mountain pastures when Chorol eloped". On her return, she asks: "Where is Chorol, I want to see her?" (p. 349). Thus, Yangchen could have been even an obstacle to this marriage.

But Yanchen's jealousy is not enough. Here, Chorol, unlike M.T., is not confirmed in her choice. M.T. acted only against a part of his wife's family and his choice was accepted by his wife's aunt and eventually by his own family. Moreover, he abided by certain rules even though he hadn't really gone through a traditional marriage and he had "legalized" this love match through his wife's aunt's help. Chorol's case is not that of Tashi's. The latter may have doubts about her status, but her family reassures her.

Here we see none of this: Chorol is really rejected and if all of the previous analyses are accurate, in the former situation she was simply incurable. It is extremely interesting to note that when Chorol is possessed (possession occurring in the village alone), it is by five unidentified neighbors. Thus, in a very important sense it is the village as a whole that rejects her because she doesn't fit in any longer.

Things sorted themselves out only later, when Chorol began to fit in again in both a literal and figurative sense. Her father-in-law put up the couple in a house next to his in his own village. Father and daughter reconciled. Chorol reintegrated the patrilocal norm.

Thus, it appears that gongmo cases are connected with the regulation of a society's order. The social circle manipulates the victim through the possession fit. The therapeutic effectiveness ensues. The individual can be reintegrated and wholly reassured (the case of Tashi), confirmed within the circumstances of a certain nonconformity (the case of M.T.) or finally excluded until she makes the necessary amends (the case of Chorol).

This article tries to shed some light on the question: Can the interpretation of the ethnologist be accepted by the native? With regard to the above examples, the answer is obviously no. Neither Tashi, nor M. T., nor Chorol can 
admit that they have not been possessed, or that they are the ones who have problems of social and familial identity, although they are aware of being in an unstable position in relation to the norm (in any case, this applies to Chorol and M.T.).

Possession as a manifestation of unstable social identity, helps to "cure" an individual without making it necessary to question his belief in gongmo, or his certitude of having been possessed. This is because the possessors, Diskit, M.T.'s ex-fiancée and Yangchen have indeed good reason for being jealous of their so-called victim, and it is not related in any way with a projection of paranoia, for example. If the ethnologist finds it necessary to reverse the situation by explaining that the "possessed" are the "sick ones", he is not for all that, in the same position as the psychoanalysts, for whom the patient himself is the one who must put into words his repressed desire in order to be cured. This is because there is no repressed desire with the victims of the gongmo, on the contrary they are people who take the initiative of action (in the three cases, the action is marriage) and it is this very accomplishment of a desire which creates problems.

As for the victims of the gongmo, some elements remain non-conscious - the three victims express their uneasiness, and all three are led to cure it with the help of the family and social circles which induce them to create a more viable/livable position around them (that is to say acceptable to the social surroundings).

\section{Patrick Kaplanian}

Translated from French by Gloria Raad

\section{References}

Brauen, Martin, 1980, Feste in Ladakh. Graz

Corin, Ellen, 1985, «La question du sujet dans les thérapies de possession ». Psychoanalyse 3: pages 5366. Bruxelles.

Day, Sophie, 1989, Embodying spirits, village oracle and possession ritual in Ladakh North India. Ph.D. Manuscript: London School of Economics

Kaplanian, Patrick, 1981, Les Ladakhi du Cachemire. Paris: Hachette.

Kaplanian, Patrick, 1983, Quelques aspects du mythe et des structures mentales au Ladakh. Recent research on Ladakh (proceedings of the first colloquium on Ladakh). Cologne: Weltforum Verlag.

Kaplanian, Patrick, 1990, «La maladie en tant que (s)notpa ». Recent research on Ladakh (proceedings of the third colloquium on Ladakh), Dresde.

Phylactou, Maria, 1989, Household organisation and marriage in Ladakh, Indian Himalaya. Ph.D. Manuscript, London School of Economics. 